DOI: https://doi.org/10.46991/AFA/2021.17.2.100

\title{
A CROSS-CULTURAL STUDY OF REFUSAL STRATEGIES OF AMERICAN AND ARMENIAN ENGLISH SPEAKERS
}

\author{
Gohar Hovsepyan* \\ Yerevan State University
}

\begin{abstract}
Several studies have been carried out on refusal strategies that native and nonnative English speakers employ to mitigate potential threat to listener's face when forming refusals to various speech acts, such as requests, offers, invitations, etc. This study adds the perspective of Armenian English speakers in using such mitigation strategies. The objective of the study is to identify similarities and differences in the use of various politeness strategies used in refusal acts by native English speakers (NES) and Armenian non-native English speakers (ANNES) with the aim of establishing the extent of cultural impact on pragmatic competence of ANNES. Language data was collected among 24 Armenian English speakers of high level of English proficiency and 15 American English speakers. A modified version of the Discourse Completion Test (DCT) developed by Beebe, Takahashi, and Uliss-Weltz (Beebe et al., 1990) was used to collect data. Along with considerable similarities in the use of politeness strategies in refusals between the two groups which indicate the high degree of pragmatic competence of ANNES, the analysis of the data also revealed some differences which attest to certain impact of the Armenian culture on this competence. The differences are mainly observed in frequency of use and in the content of the same strategies used by the two groups.
\end{abstract}

Keywords: refusal acts, face threatening acts, politeness strategies, cross cultural studies, EFL.

\section{Introduction}

Cross-cultural communication skills are required whenever people from different cultures and speaking different languages get to communicate with each other. Getting invited or being offered or requested are common acts in our everyday life, and often times people feel the need to refuse such acts they

\footnotetext{
*gohar.hovsepyan@ysu.am

This work is licensed under a Creative Commons Attribution-NonCommercial 4.0 International License.
}

Received: 01.07.2021

Revised: 24.08 .2021

Accepted: 22.09 .2021

(C) The Author(s) 2021 
receive. As human beings, we have the want and expectations to be appreciated and respected. Thus, it is important to acquire pragmatic knowledge of the communication style of the cultures with representatives of which one gets into contact, the English speaking culture in our case. One needs to know what refusal form is appropriate in a given situation, i.e. to develop deeper cultural awareness, as well as pragmatic competence in cross cultural communication. Refusing should be expressed in a way not to offend the interlocutor and it is practiced by different politeness strategies.

Several studies have already testified to the existance of pragmatic transfer from native language (L1) to foreign language (L2), thus we do not set a goal to prove that such transfer takes place in non-native English speakers' communication style. The aim of this study is to investigate the extent of such sociocultural impact on the pragmatic competence of Armenian foreign language speakers. Our objective is to explore the cultural differences or similarities in making refusals between Armenian and American cultures, specifically identifying similarities and differences in the use of politeness strategies in forming acts of refusal by U.S. native and Armenian non-native English speakers. Refusals were chosen for our investigation since they are intrinsically face threatening acts and call for certain mitigation strategies to redress threat to hearer's face, i.e. the public image of the interlocutor.

Refusal is, by nature, one of the most offensive speech acts, and, it is apt to damage the interlocutor's face if not performed politely. Therefore, various politeness strategies are employed to cushion its negative impact. Each language, however, realizes politeness differently. For example, being direct can be regarded as polite in a certain culture, but it might be considered impolite in another. Hence, to avoid breakdowns in communication, it is important to explore how cultural background can affect one's choice of language means and strategies in forming various speech acts, including acts of refusal and, ultimately, one's pragmatic competence in communicating in L2. This gains special importance today with current technical advancement and social media communication trends that make cross cross-cultural communication an integral part of our life.

The material was collected through a total of 39 questionnaires based on a modified DCT test, which elicited 72 refusals from Armenian and 45 refusals from American English speakers. The questionnaire consisted of three invitations to persons of different social statuses to which the respondents were requested to refuse. Thus the pragmatic factor of social status is another focus 
of our investigation. The relatively small sampling size allows for only limited generalizations of the results. Nonetheless, a number of noteworthy patterns of certain similarities and differences were observed between the two cultures, which testify to the cultural impact on L2 use.

\section{Refusal acts}

Good communication requires not only linguistic knowledge, but also an understanding of social, cultural and other pragmatic factors in a situation. Our choice of language means can make a big difference in maintaining relationships, conveying our intentions and expressing our feelings accurately. According to Yule (1996), pragmatics has more to do with the analysis of what people mean by their utterances than what the words or phrases in those utterances might mean by themselves. This perspective then raises the question of what defines the choice of language means to form the speech acts we intend to perform. Distance between interlocutors, cultural and social background, status, gender, educational level are only a few of the important pragmatic factors that influence the choice.

Searle and Vanderveken define the speech act of refusal as follows: "The negative counterparts to acceptances are rejections and refusals. Just as one can accept offers, applications, and invitations, so each of these can be refused or rejected" (Searle, \& Vander- veken, 1985, p.195). According to MerriamWebster Dictionary (2005), refusal means expressing oneself as unwilling to accept, to do or comply with, or deny. Therefore, refusal is a face threatening act. Hence, there is a need to put politeness strategies into action in order to mitigate the threat, i.e. to soften what the hearer might regard as an infringement on him/her.

The speech act of refusals represents one type of dispreferred response. Refusals are one of the relatively small number of speech acts which can be characterized as a response to another's act, rather than as an act initiated by the speaker (Houck \& Gass, 1999, p. 2). They occur as negative responses to other acts such as requests, invitations, offers, and suggestions (ibid.). In response to requests, invitations, offers, and suggestions, acceptance or agreement are usually preferred, and refusing or rejecting are not. Refusals or rejections can mean disapproval of the interlocutor's idea and therefore, a threat to the interlocutors face, hence they are often formed indirectly or are accompanied by mitigation or explanation. On the other hand, acceptance or agreement tend to be formed by direct strategies. 
Refusals have been one of the most studied topics in pragmatics and are very important because of their communicative role in everyday social interaction. They are considered to be face-threatening acts because they contradict the listener's expectations. As stated above, they are often realized through indirect strategies, thus they require a high level of pragmatic competence (Chen, Lei, \& Yanyin, 1995). They are considered to be a speech act by which "a speaker fails to engage in an action proposed by the interlocutor" (ibid., p. 121).

Furthermore, what is considered an appropriate refusal behavior may vary across cultures and pragmatic transfer is likely to occur as learners rely on their cultural values "in carrying out complicated and face-threatening speech acts like refusals (Beebe et al., 1990, p. 68). Therefore, appropriate understanding and production of refusals require a certain amount of culture-specific knowledge. The interlocutors are socially expected to know when to use the appropriate form of refusals in a certain context. Depending on ethnicity and cultural-linguistic values, the speaker must know the appropriate form and its function. On the whole, refusals are complicated due to the fact that they are influenced by some social factors, namely, age, gender, level of education, social distance, and power (Fraser, 1990; Smith, 1998) and because they require sequences of negotiation. In addition, it is even hard to reject requests, suggestions, and offers in a foreign language due to the fact that misunderstandings may arise if one does not use pragmatic knowledge appropriately. More crucially, refusing others' suggestion, offer and request without hurting their feelings is of great importance since the "inability to say 'no' clearly has led many non-native speakers to offend their interlocutors" (Ramos, 1991).

\section{Politeness strategies in refusal acts}

As discussed above, refusals are commonly believed to be delicate speech acts to perform, since positive responses such as acceptance and agreement are usually preferred. For this reason, refusals often involve various indirect strategies to be polite and avoid a failure in interpersonal relationships, which requires a high level of pragmatic competence (Salazar-Campillo, 2009). Therefore, it is important to examine the concept of politeness in more detail in order to see how it may influence refusals. An important issue to be considered by speakers is to acknowledge and respect interlocutor's individuality and freedom of choice and their system of values and beliefs. 
In an early attempt to classify the realization of refusals, Rubin (1983) claimed that there were the following 7 ways of refusing across a number of cultures:

1. be silent, hesitate, show a lack of enthusiasm;

2. offer an alternative;

3. postponement;

4. put the blame on a third party or something over which you have no control

5. avoidance;

6. general acceptance with excuses;

7. say what is offered is inappropriate.

The most influential and best known study on refusal strategies, though, is Beebe, Takashaki and Uliss-Weltz's Pragmatic Transfer in ESL Refusals (1990) with its famous taxonomy of these strategies. The authors examine how Japanese learners of English refuse requests, invitations, offers and suggestions by means of a Discourse Completion Test (DCT). Their classification is divided into semantic formulas, i.e., those expressions used to perform a refusal, and adjuncts, that is, expressions which accompany a refusal but which cannot by themselves be used to perform a refusal. On the basis of an analysis of native speaker refusals, Beebe and Takashaki were able to show that they are performed by means of fairly limited set of direct and indirect "semantic formulas". Individual refusals are made up of different selections from these formulas in accordance with the status and power relationships holding between speaker and hearer. Semantic formulas with both components - main acts and adjuncts - developed by Beebe and Takashaki are illustrated as follows:

\section{Direct}

A. Performative (e.g., "I refuse.")

B. Nonperformative

1. "No"

2. Negative willingness/ability (e.g., "I can't."; "I don't think so.”)

\section{Indirect}

A. Statement of regret (e.g., "I'm sorry. .."; "I feel terrible. ..”).

B. Wish (e.g., "I wish I could help you. ..").

C. Excuse, reason, explanation (e.g., "My children will be home that night."; "I have a headache.").

D. Statement of alternative (e.g., "I'd rather. .." ; "I'd prefer. . ."). 
E. Set condition for future or past acceptance (e.g., "If you had asked me earlier, I would have.").

F. Promise of future acceptance (e.g., "I'll do it next time"; "I promise I'll. .." or "Next time I'll." using "will" of promise or "promise").

G. Statement of principle (e.g., "I never do business with friends.").

H. Statement of philosophy (e.g., "One can't be too careful.”).

I. Attempt to dissuade interlocutor (such as threat or statement of negative consequences to the requester e.g., "I won't be any fun tonight." to refuse an invitation).

J. Acceptance that functions as a refusal:

1. unspecific or indefinite reply,

2. lack of enthusiasm.

K. Avoidance:

1. non-verbal (silence, hesitation, inaction, physical departure),

2. verbal (topic switch, joke, repetition of part of request, etc., postponement (e.g., "I'll think about it.").

Adjuncts to a refusal do not form part of the refusal itself, but they are external modifications of the main refusal.

A. Statement of positive opinion/feeling or agreement ("That's a good idea. ..'I'd love to. ..").

B. Statement of empathy (e.g., "I realize you are in a difficult situation.").

C. Pause fillers (e.g., "uhh"; "well”; "oh"; "uhm").

D. Gratitude/Appreciation.

Due to their face-threatening nature, refusals are especially sensitive, and a pragmatic breakdown in this act may easily lead to unintended offence and/or breakdown in communication. Refusals by nature are complex; they are often negotiated over several turns and involve some degree of directness and indirectness, usually varying in the degree of directness and indirectness depending on the status and age of the interlocutors and the cultural context.

According to Houck and Gass (1996), when one decides not to accept an initiated act, she/he can generally take three possible refusal approaches:

- rejection,

- postponement,

- proposal of alternative.

As Houck and Gass (1999) state, part of the complexity of refusals lies in the fact that they may involve a long negotiated sequence and, because they function as a second pair part, they preclude extensive planning on the part of 
the refuser. Due to the complex nature of refusals as dispreferred seconds, refusals were not approached as a speech event involving a long negotiated sequence.

\section{Cross-cultural study of refusal strategies mitigating threat to face}

Cross-cultural studies on refusals show that different cultures perform refusals differently. Their degree of directness in refusals, their sensitivity to social variables, and their performance in terms of the content of strategies might vary.

Several cross-cultural refusal studies have clearly shown that there are differences between the American and the non-American refusals in terms of the order, frequency, and the content of the semantic formulas and adjuncts. These studies suggest that in general, Americans tend to be direct because they see directness as being honest and as an individual right to refuse (e.g., Beebe et al.,1990; Chang, 2009; Chang, 2011; Kwon, 2004). Differences in clarity and content of reasons and excuses were also shown to exist between the Americans and non-Americans. Reasons and excuses given for the refusal are often inappropriate from an American viewpoint because they are unclear or untrue (Beebe et al., 1990; Chang, 2009; Chang, 2011; Kwon, 2004). In American culture, if one lies or makes up a reason, one would lose face, but one does not lose face even if he/she refuses honestly as long as the interlocutor's feelings are taken into account and refusal is mitigated or negotiated for an acceptable alternative. This may be the reason why the excuse or reason for a direct refusal by Americans is generally clear and honest. On the other hand, refusals in other cultures are less direct than the Americans', as a direct refusal seems to threaten the hearer's face and thus damage relationship (e.g., Beebe et al., 1990; Chang, 2009; Kwon, 2004). Therefore, a direct refusal statement is often avoided, and instead a variety of other strategies (indirect and adjunct) are employed to maintain politeness. Our findings reiterate these results in regard to the content of reason/excuse for refusals to invitations: Americans tend to provide more honest reasons for refusals than Armenians: e.g.

1. I would love to have dinner with you. I hope you know how much I enjoy spending time with you and how much I care about you. . But after the last time with (your husband) I'm not sure if it's a good idea for me to join you for this dinner party. What do you think? . . How about if I 
don't join you for the party and instead we meet for a walk and lunch on Sunday? (NES to friend)

2. Alice, Thank you for the invitation. I look forward to working with you once the contracts are signed- but our Board of Directors and our tax accountants have determined that accepting such individual gifts is inappropriate and possibly a violation of our corporate tax rules. Let's meet for coffee sometime and catch up. (NES to person of lower status)

3. Thank you for the invitation. I would come with great pleasure, but my mother is coming from overseas and I need to collect her from the airport. Wish you a nice and enjoyable evening. (ANNES to friend)

As for sheer numbers of the use of either specific or general reasons, and the direct strategy of expressing negative ability (I can't, I am afraid I won't be able to), there are no apparent differences in the two groups of responses. Interestingly, though, our findings revealed a difference in the content of direct refusal acts formed by the two groups: if direct refusals expressed by negative ability were similarly used by the two groups, direct refusals expressed by the performative verbs refuse or turn down were observed only with Armenian English speaking respondents: e.g.

1. I am really thankful for your invitation. But I am afraid I have to refuse, because I have some problems. I will be glad if you invite me next time. (ANNES to person of higher status)

2. Dear Mr. ... I am very pleased that you have invited me too. It would be my pleasure to come, but I sincerely apologise to disappoint you. I have an important appointment that day. I will have to refuse this time. (ANNES to person of higher status)

3. I really appreciate it but I think for now I have to turn you down as I am and will be pressed for time in the near future. As soon as I am free, I will let you know. (ANNES to person of lower status)

Research findings also reveal a distinct difference in the use of politeness strategy of offering an alternative in refusal acts by the two groups (NES and 
ANNES): only $6 \%$ of Armenians as opposed to $38 \%$ of Americans included an offer of alternative in their refusals to invitations: e.g.

1. Let's talk over the possibilities of purchasing your business's products in the afternoon sometime soon. For example, how about meeting next Wednesday or Thursday afternoon in my office or at the coffee shop downstairs. I'm free those days between 3:00 and 5:00. (NES to person of lower status)

2. When you have recovered from the party, let's get together for coffee and catch up. Do you think next Thursday might work? (NES to a friend)

3. What if we two have lunch during the week at (the restaurant that we two love to attend).(ANNES to friend)

Notably, Americans used the strategy of offering an alternative only in refusals to friends and persons of lower status but not to persons of higher status.

Instead of the strategy of offering an alternative, Armenian English speakers used other adjuncts or politeness strategies more frequently compared to American speakers, including:

a) the strategy of promise or vague promise of future acceptance: e.g.

1. I will be glad if you invite me next time. (ANNES to person of lower status)

2. Maybe we can meet next time. (ANNES to friend)

3. As soon as I am free, I will let you know. (ANNES to person of lower status)

b) the strategy of set condition for past acceptance: e.g.

1. If I had known it earlier, we would have cancelled all our plans so as to come to your party. (ANNES to person of higher status)

2. You should have told me earlier as I have already booked a table at a restaurant to celebrate my parent's $25^{\text {th }}$ wedding anniversary. (ANNES to person of higher status)

c) the use of the adjunct of apology: e.g. 
1. Sorry dear, I wish I could make it, but I can't. (ANNES to friend)

2. I am so sorry, but I am already invited to the wedding of my cousin. (ANNES to person of higher status)

In order to mitigate the refusal, another common strategy - expressing $a$ positive opinion or feeling - is often used in Americans' refusals (e.g., Beebe et al.,1990; Chang, 2009; Chang, 2011; Kwon, 2004). The analysis of the material of this research supports this finding - specifically $70 \%$ of Americans versus $53 \%$ of Armenians used this strategy to soften possible threat to interlocutor's face caused by refusal to their invitation: e.g.

1. ... I'll have my assistant contact you in the next few weeks to set up a meeting to finalize the contract. Thank you again for the invitation. I can tell you are a person of good taste - that is such a fine restaurant. (NES to inferior)

2. Thank you! I'm honoured to be among the top executives invited to your home. That is wonderfully spontaneous of you and [wife] to host a party next Sunday. I am afraid I cannot be so spontaneous. (NES to superior)

3. That sounds great! Oh actually though, I think we got plans already. (NES to friend)

Despite the slight difference in numbers, there is no apparent difference in the use of form and content of this mitigating strategy in the refusals formed by Armenian respondents: e.g.

1. I have guests today, otherwise I would accept your invitation with great plesure. (ANNES to inferior)

2. Thank you very much for the invitation. I am honoured to be invited to the party and am very excited for having the chance to meet your spouse. Unfortunately... (ANNES to superior)

3. That's a really great idea! ... I would love to visit you for sure but... (ANNES to friend)

In regard to the use of the politeness strategy of adding gratitude/appreciation as an adjunct to the refusal act, this research finds almost similar use in percentage of the two groups, with Americans using this 
strategy a little more frequently (62\%) than Armenians (44\%). However, the distribution of this quantity is different in different situations, depending on social status. If Armenians used gratitude in $58 \%$ of refusals made to persons of lower status, $90 \%$ of Americans did so. On the other hand, less than $20 \%$ of Americans included gratitude in refusal acts made to friends, as opposed to 33 $\%$ of the refusals made to friends by Armenians. As to the use of gratitude in refusals made to persons of higher status, it was found in $78 \%$ of refusals by Americans and in $48 \%$ of refusals by Armenians. Thus, according to our results, Americans rarely use gratitude as a politeness strategy when refusing friends, but will almost deffinitely include it in refusals made to persons of lower or higher status, whereas Armenians tend to have less variation along social line and will typically include gratitude in their refusal as a politeness strategy in almost every second refusal (58\%).

In terms of Americans' sensitivity to relative social status, the studies show mixed results. Beebe et al. (1990) found that Americans refused differently based on whether the interlocutor was of equal or unequal status, however, Kwon (2004) reported that American participants did not change their approach significantly according to the distance and power of interlocutors. Our findings concur with the results produced by the study of Beebe et al. (1990). For instance, our discussion above on Americans' use of the strategy of offering an alternative only with inferiors but not with superiors is one evidence supporting the claim of differences in NES' refusal strategies depending on social status factor.

Regarding non-American's sensitivity to relative social status, several patterns were reported. In some cultures, such as Japanese and Iranian, it appears that different refusal strategies are used depending on whether the social status of the interlocutor is high, equal, or low (Beebe et al., 1990). In other cultures such as Korean and Mexican, it is reported that they are highly sensitive to a higher status person when refusing (Félix-Brasdefer, 2008; Kwon, 2004). Armenian respondents proved to be less sensitive to social status in terms of types of politeness strategies they used in refusals. The discussion of the gratitude strategy above is one evidence showing similar percentage of usage of this strategy to refuse people of different social statuses. However, the content of the same strategy often varied depending on that status: For instance, the same strategy of statement of positive opinion was different in content depending on whether the Armenian English speaker refused a person of higher or lower status: e.g. 
1. Thank you for the invitation, but no need to take the trouble. We can discuss the issue at my office. (ANNES to person of lower status)

2. Dear boss it would be a great honor for me to join your little party with my spouse. Unfortunately... (ANNES to person of higher status)

3. Thank you very much for the invitation. I am honoured to be invited to the party, and am very excited for having the chance to meet your spouse. Unfortunately... (ANNES to person of higher status)

In another cross-cultural study, Nelson et al. (2002) investigated similarities and differences between Egyptian Arabic and American English refusals. Results indicated that both groups use similar strategies with similar frequency in making refusals, counter to Al-Issa's (2003) findings where Jordanians used more indirect strategies than Americans. The findings, however, suggest that although methods such as the DCT may be appropriate for collecting pragmalinguistic data, they fail to reveal the sociopragmatic complexities of face-threatening acts (e.g. refusals). The Egyptians indicated that they would not make refusals in some of these situations, like refusing an invitation from their boss. Notably, in our research, it was an American respondent who refused to make a refusal to the invitation of the boss. Thus, the sociopragmatic complexities that indicate the participant's informed decision not to refuse an invitation from their boss cannot be revealed by using the DCT alone.

More recently, Felix-Brasdefer (2008) examined refusals in two sociocultural contexts of Mexico and Dominican Republic, based on the same DCT test method. The results showed that although situational variation was the norm between both groups, the Mexicans used significantly more refusal strategies in relation to the status of interlocutors. It is, therefore, likely that L2 learners may rely on their language pragmatic knowledge to perform the target language refusals which may result in pragmatic failures.

As discussed previously, several studies suggest that English learners' L2 pragmatic competency is clearly affected by their L1 pragmatic strategy use, and they appear to find the characteristics of American refusals problematic; for example, by not giving clear refusal statements and by providing reasons that could be interpreted as dishonest (Bardovi-Harlig \& Hartford, 1991; Beebe et 
al., 1990; Chang, 2009; Chang, 2011; Kwon, 2004). Other factors that may affect L2 pragmatics include proficiency level, the length of residency in the target community, and the learner's first language (L1). There is mixed evidence that the higher proficiency-level of English learners will transform to a higher pragmatic competency in the L2 (Houck, \& Gass, 1999). A single study by Félix-Brasdefer (2004) suggests that the length of residency in the target community affects the development of refusal strategies that are appropriate in the target language. According to Félix-Brasdefer (2004), learners who spent less than 5 months abroad tended to refuse directly and briefly, while the learners who spent 9 months or more in the target community demonstrated refusal strategies that were similar to the patterns of the native speakers.

\section{Conclusion}

Analysis of the results of the current research demonstrated many similarities in the use of politeness strategies by American and Armenian English speakers in their refusals to invitations, especially in regard to the types of politeness strategies and adjuncts that they used to cushion intrinsic threat to the face of interlocutors by their refusals.

However, the findings also revealed certain differences between the use of politeness strategies by the two groups, specifically:

1) in frequency of use of the same types of politeness strategies by representatives of NES and ANNES. For instance, more Americans include the strategy of offering alternative in their refusals than Armenians. On the other hand, more Armenian respondents use the strategies of offering set condition for past acceptance, promise for future acceptance, and offering apology than American respondents. Additionally, Americans rarely use gratitude as a politeness strategy when refusing friends, but will almost definitely include it in refusals made to persons of lower or higher status, whereas Armenians tend to have less variation along social line and will typically include gratitude in their refusal as a politeness strategy in almost every second refusal (58\%);

2) in the content of one and the same strategy. For instance, Americans tend to provide more honest reasons for refusals than Armenians. Besides, if direct refusals expressed by negative ability are similarly used by the two groups, direct refusals expressed by the performative verbs refuse or turn down are observed only with Armenian English speaking respondents; 
3) in the use of the same strategies along social line by the two groups. Armenian respondents proved to be less sensitive to social status, using the same types of politeness strategies in refusals to persons of different status. However, the content of the same strategy often varied depending on that status, and this indicated commonness of usage by the two groups.

To sum up, being a complex task, refusing requires a high level of communicative competence in a foreign culture. The findings of this research demonstrate that, even if not to a high degree, Armenian English language learners' own culture impacts this competence. In order to avoid pragmatic failure, speakers need to understand fully both socio-cultural strategies used by most native speakers and the rules for their appropriate implementation. Consequently, learners' exposure to the way refusals are realized in different contexts is of utmost importance in EFL instructional settings.

\section{References}

Al-Issa, A. (2003). Sociocultural transfer in L2 speech behaviors: Evidence and motivating factors. International Journal of Intercultural Relations, 27(5), 581-601.

Bardovi-Harlig, K., \& Hartford B.S. (1991). Saying "No": Native and nonnative rejections in English. In L. Bouton, \& Y. Kachru (Eds.), Pragmatics and language learning, Monograph (pp. 41-57). UrbanaChampaign, IL: DEIL

Beebe, L., M., Takahashi, T., \& Uliss-Weltz, R. (1990). Pragmatic transfer in ESL refusals. In R. C. Scarcella, E. Andersen, \& S. D. Krashen (Eds.). Developing communicative competence in a second language (pp.55-73). New York, USA: Newbury House.

Chang, Y. (2009). How to say no: An analysis of cross-cultural difference and pragmatic transfer. Language Sciences 31(4), 477-493.

Chang, Y. (2011). Refusing in a foreign language: An investigation of problems encountered by Chinese learners of English. Retrieved from https://www.researchgate.net/publication/276941276

Chen, X., Lei, Y., \& Yanyin, Zh. (1995). Refusing in Chinese. In Gabriele Kasper (Ed.). Pragmatics of Chinese as Native and Target Language (pp.119-163). Manoa, HI: University of Hawai'i Press. 
Félix-Brasdefer, J. C. (2004). Interlanguage refusals: Linguistic politeness and length of residence in the target community. Language Learning, 54, 587-653.

Félix-Brasdefer, J. C. (2008). Sociopragmatic variation: Dispreferred responses in Mexican and Dominican Spanish. Journal of Politeness Research, 4, 81-110.

Fraser, B. (1990). Perspectives on politeness. Journal of Pragmatics, 14 (2), 219-236.

Houck, N., \& Gass, S.M. (1996). Non-native refusals: A methodological perspective. In S. Gass, \& J. Neu (Eds.). Speech acts across cultures: Challenges to communication in a second language. (pp. 45-64). New York: Mouton de Gruyter.

Houck, N. \&. Gass, S, (1999). Interlanguage refusals: A cross cultural study of Japanese-English. Berlin: Mouton de Gruyter.

Kwon, J. (2004). Expressing refusals in Korean and in American English. Multilingua - Journal of Cross-Cultural and Interlanguage Communication, 23 (4), 339-364.

Merriam-Webster Inc. (2005). The Merriam-Webster dictionary. Springfield, Mass: Merriam-Webster.

Nelson, G. L., Al Batal, M., \& El Bakary, W. (2002). Directness vs. indirectness: Egyptian Arabic and US English communication style. International Journal of Intercultural Relations, 26 (1), 39-57. Retrieved from https://www.sciencedirect.com/science/article/abs/pii/S0147176701000372

Ramos, J. (1991). Pragmatic transfer in refusals among Puerto Rican teenagers speaking English. Unpublished Doctoral dissertation, Teachers College, Columbia University.

Rubin, J. (1983). How to tell when someone is saying "no" revisited. In N. Wolf son, \& E. Judd (Eds.), Sociolinguistics and Language Acquisition. (pp. 10-17). Rowley, MA: Newbury House.

Salazar-Campillo, P. (2009). Refusal strategies: A proposal from a sociopragmatic approach, Revista Electrónica de Lingüística Aplicada 8. Retrieved from, https://www.researchgate.net/publication/41583825

Searle, J., \& Van der Veken, D. (1985). Foundations of illocutionary logic. England: Cambridge University Press 
Smith, C. (1998). Can adults "Just say no?" How gender, status and social goals affect refusals. Unpublished Doctoral dissertation, University of South Florida.

Yule, G. (1996). Pragmatics. London: Oxford University Press.

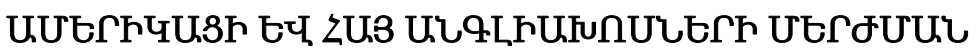

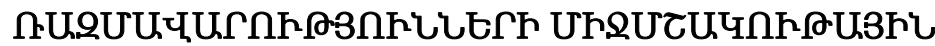

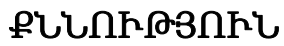

\section{qnhup Znulutịjuiq}

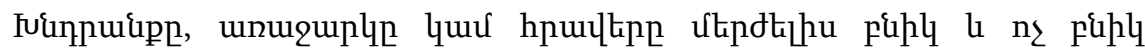

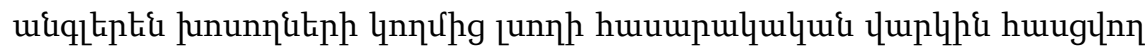

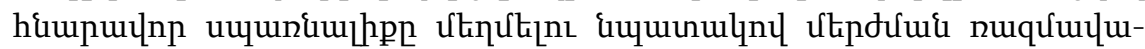

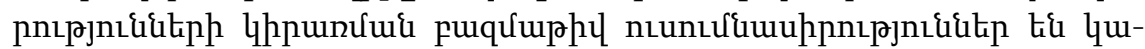
unupltil:

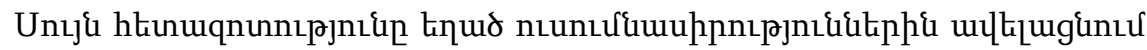

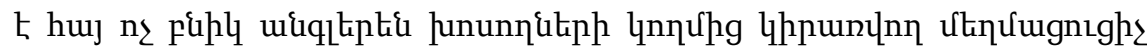

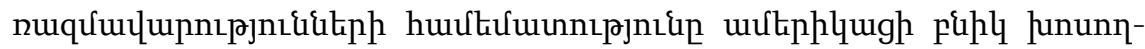

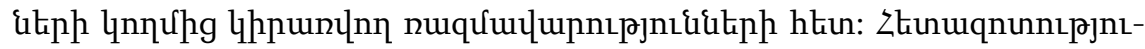

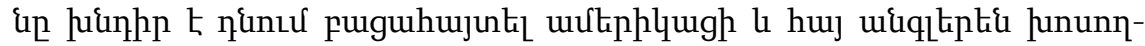

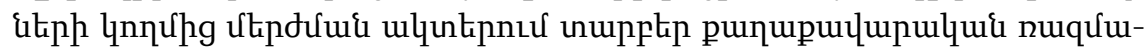

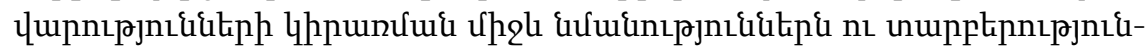

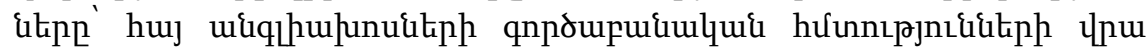

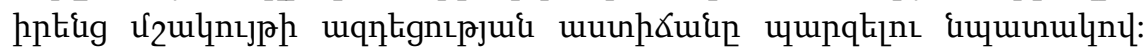

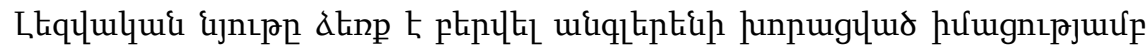

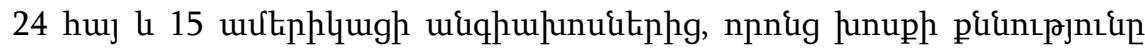

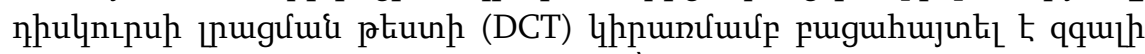

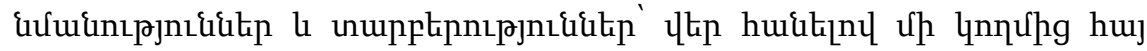

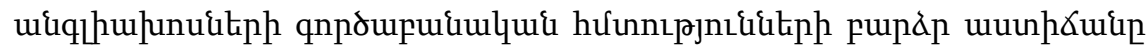

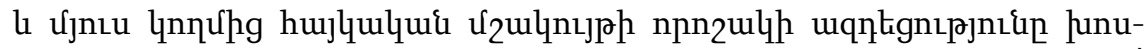

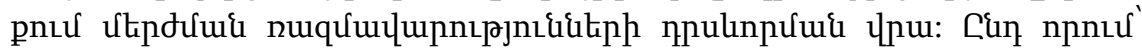

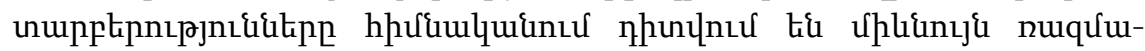

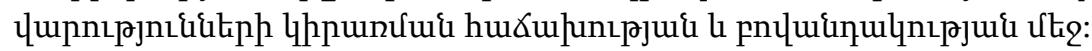

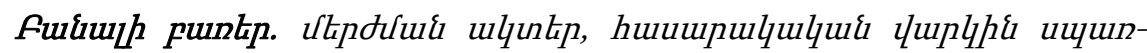

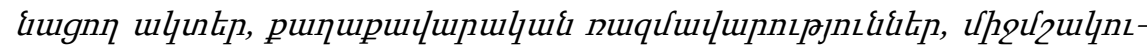

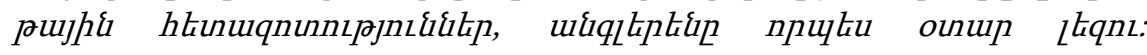

